\title{
Effects of Electrolyte Temperature during Anodization on Properties of $\mathrm{ZrO}_{2}$-coated Al Foils
}

\author{
Received November 14, 2019; accepted December 3, 2019
}

\author{
Kaiqiang Zhang ${ }^{\mathrm{a}}$ and Sang-Shik Park ${ }^{\mathrm{b}, *}$ \\ a Department of Materials Science and Engineering, Research Institute of Advanced Materials, Seoul National University, Seoul O8826, \\ Republic of Korea \\ ${ }^{\mathrm{b}}$ School of Nano Materials Engineering, Kyungpook National University, Gyeongsangbuk-do 37224, Republic of Korea
}

\section{*Corresponding author E-mail: parkss@knu.ac.kr}

\begin{abstract}
The effects of electrolyte temperature during anodization on the microstructure and electrical properties of the $\mathrm{ZrO}_{2}$ coated $\mathrm{Al}$ foils were investigated. The specimens were prepared by coating $\mathrm{ZrO}_{2}$ sol on etched $\mathrm{Al}$ foils and anodization in MPD-boric acid electrolytes at 30, 60, and $90{ }^{\circ} \mathrm{C}$, respectively. Anodization potential was $700 \mathrm{~V}$. The thickness of oxide layer anodized increased with increasing the electrolyte temperature. In contrast, the crystallization of $\mathrm{ZrO}_{2}$ and $\mathrm{Al}_{2} \mathrm{O}_{3}$ decreased at higher anodizing temperature. Compared with the specific capacitance of the sample anodized at $90{ }^{\circ} \mathrm{C}$, the specific capacitances of which anodized at 30 and $60{ }^{\circ} \mathrm{C}$ are enhanced about $12.8 \%$ and $8.8 \%$, respectively. Therefore, the anodization at $30{ }^{\circ} \mathrm{C}$ can effectively improve the specific capacitance of the samples, and save the thermal energy during anodization.
\end{abstract}

Keywords: 2-methyl-1, 3-propanediol, Anodization, $\mathrm{ZrO}_{2}, \mathrm{Al}_{2} \mathrm{O}_{3}$, Specific capacitance

\section{Introduction}

With the advance of exploitation on new energy resources, energy-storage technology correspondingly acts a significant role in our life. Capacitors as well as batteries known as two kinds of essential energy-storage devices are now researched by numerous experts. In comparison with batteries, capacitors possess an even higher power, and the basic construction of capacitors is a sandwich structure of anode/dielectrics/cathode. The capacitances of the capacitors can be characterized by $C=\varepsilon_{0} \cdot \varepsilon_{\mathrm{r}} \cdot S / d$, where $C$ is the capacitance, $\varepsilon_{0}$ is the dielectric constant in vacuum, $\varepsilon_{\mathrm{r}}$ is the dielectric constant of the dielectrics in capacitor, $d$ is the thickness of the dielectrics, and $S$ is the effective surface area of the electrode. Al electrolytic capacitor as one kind of economic and environment-friendly energy-storage device has been widely applied in electronics used in defense, aerospace, and transportation fields, etc. The key part of $\mathrm{Al}$ electrolytic capacitor is the $\mathrm{Al}_{2} \mathrm{O}_{3}$ dielectrics formed by anodization in various electrolytes such as phosphoric acid solution [1], boric acid solution [2], malonic acid solution [3], ammonium penta-borate solution [4], and citric acid solution [5], etc. Anodization is an economic and convenient approach for the formation of $\mathrm{Al}_{2} \mathrm{O}_{3}$ layer, in which the $\mathrm{Al}_{2} \mathrm{O}_{3}$ is formed by the combination of $\mathrm{O}^{2-}$ ions and $\mathrm{Al}^{3+}$ ions, starting at the both $\mathrm{Al} /$ native $\mathrm{Al}_{2} \mathrm{O}_{3}$ and native $\mathrm{Al}_{2} \mathrm{O}_{3}$ /electrolyte interfaces. The properties of formed $\mathrm{Al}_{2} \mathrm{O}_{3}$ can be determined by the anodization modes consisting of galvanostatic and constant potential. In addition, the electrolyte parameters also act as a significant role in anodization process. The parameters of electrolyte during anodization such as temperature, $\mathrm{pH}$, conductivity, and viscosity, etc. can largely affect the performances of
$\mathrm{Al}_{2} \mathrm{O}_{3}$ on microstructure and electrical properties, and a lot of outstanding researches have handled these topics $[6-8]$. However, an eager requirement for the study of the electrolyte used for anodization of Al foils worked in high-voltage field is salient.

The composition and type of the electrolyte used for anodization significantly affects the anodizing efficiency and electrical properties of the Al foils. Although many electrolytes have been extensively researched [5,9-12], the withstanding voltages of anode foils formed by these electrolytes are still relatively low. So, organic electrolyte has received attention to further increase the withstanding voltage. Kinard et al. showed that when $\mathrm{Al}$ foils were anodized in borate polyester, which is a compound of boric acid and 2-methyl-1, 3-propanediol (MPD), a significantly high withstanding voltage, even higher than $3000 \mathrm{~V}$, could be obtained [13]. Based on our previous work, MPDboric acid electrolyte used for high-voltage anodization can effectively inhibit the micro-arcs caused by oxygen evolution when anodization is conducted at high voltage (over $700 \mathrm{~V}$ ) [14].

$\mathrm{ZrO}_{2}$ shows a much higher permittivity of $22-25$ than 9.8 of $\mathrm{Al}_{2} \mathrm{O}_{3}$ [15], which could effectively enhance the specific capacitance $\left(C_{\mathrm{p}}\right)$ by enlarging the $\varepsilon_{\mathrm{r}}$ of the dielectrics in conventional Al electrolytic capacitor. Simple and convenient sol-gel process was selected to prepare the $\mathrm{ZrO}_{2}$-coated $\mathrm{Al}$ foils. $\mathrm{ZrO}_{2}$-coated $\mathrm{Al}$ foils were anodized to secure appropriate withstanding voltage and $\mathrm{ZrO}_{2}-\mathrm{Al}_{2} \mathrm{O}_{3}(\mathrm{ZAO})$ composite oxide. It was generally accepted that the temperature of an electrolyte used for anodizing aluminum is one of important factors which determines the type of oxide grown on the surface. In this work, the effects of anodization temperature of MPD-boric acid electrolyte on the microstructure and electrical properties of the $\mathrm{ZrO}_{2}-\mathrm{Al}_{2} \mathrm{O}_{3}$ 
dielectrics formed on the etched $\mathrm{Al}$ foils were studied.

\section{Experimental procedure}

\section{1) Preparation}

Etched Al foils (99.99 \%, thickness: $\sim 125 \mu \mathrm{m}$, hole density: $\sim 2.0$ $\times 10^{7} \mathrm{~cm}^{-2}$, hole diameter: $1-2 \mu \mathrm{m}$, and hole length: $20-50 \mu \mathrm{m}$ ) were placed into alcohol (purity: $99.5 \%$ ) and ultrasonically cleaned for 20 min to remove surface contaminants. $\mathrm{ZrO}_{2}$ sol of $0.8 \mathrm{M}$ were prepared by mixing zirconium butoxide $\left(\mathrm{Zr}\left(\mathrm{OC}_{4} \mathrm{H}_{9}\right)_{4}, 80 \mathrm{wt} \%\right.$ in 1-butanol, Sigma-Aldrich, USA), 2-methoxyethanol $\left(\mathrm{CH}_{3} \mathrm{OCH}_{2} \mathrm{CH}_{2} \mathrm{OH}\right.$, anhydrous, $99.8 \%$, Sigma-Aldrich, USA), acetic acid $\left(\mathrm{CH}_{3} \mathrm{COOH}, 99.7 \%\right.$, Daejung Chemicals \& Metals, Korea), and nitric acid $\left(\mathrm{HNO}_{3}, 60 \sim 62 \%\right.$, Daejung Chemicals \& Metals, Korea). Finally, the transparent precursors were aged for 3 days. The $\mathrm{ZrO}_{2}$ sol was coated on the surface of the etched $\mathrm{Al}$ foils by vacuum infiltration, which can be described in detail as a bath with $\mathrm{Al}$ foils was placed into a chamber, thereafter, evacuation was carried out. Subsequently, $\mathrm{ZrO}_{2}$ sol was injected into the bath, followed by ventilated and the etched $\mathrm{Al}$ foils were lifted from the $\mathrm{ZrO}_{2}$ sol bath. The $\mathrm{ZrO}_{2}$ film on the etched $\mathrm{Al}$ foils was dried at $100{ }^{\circ} \mathrm{C}$ for $1 \mathrm{~h}$ and annealed at $500{ }^{\circ} \mathrm{C}$ for $10 \mathrm{~min}$ in ambient environment. The same coating process was repeated four times to achieve the optimal thickness. Subsequently, the $\mathrm{ZrO}_{2}$-coated Al foils were firstly anodized at a mode of constant current $\left(0.1 \mathrm{~A} / \mathrm{cm}^{2}\right)$ until the settled voltage $(700 \mathrm{~V})$, subsequently, the anodization at a fashion of constant voltage was carried out, lasting until the current flowing through the sample is $0.01 \mathrm{~A}$ in MPD-boric acid electrolyte of 30, 60, and $90{ }^{\circ} \mathrm{C}$, respectively. The anodization electrolytes were MPD:boric acid electrolyte $\left(100 \mathrm{~g}\right.$ of $\mathrm{H}_{3} \mathrm{BO}_{3} / 1 \mathrm{~L}$ of $\mathrm{H}_{2} \mathrm{O}$ ) with volume $\%$ ratios of $3: 10$. The MPD-boric acid electrolyte must be kept at greater than or equal to $30{ }^{\circ} \mathrm{C}$ to avoid the precipitation of boric acid [Fig. 1(a)]. Lastly, the anodized samples were annealed in a furnace of $500{ }^{\circ} \mathrm{C}$ for $2 \mathrm{~min}$ for characterization.

\section{2) Characterization}

Crystalline structure of the oxide layer formed on the $\mathrm{Al}$ foils was analyzed using X-ray diffraction (XRD, X'pert Pro MRD, PANalytical). The cross-sectional structures of the coated layer and anodized oxide layer were characterized using field emission-scanning electron microscopy (FE-SEM, JSM-6700E, Jeol) and field emission-transmission electron microscopy (FE-TEM, titan G2 ChemiSTEM Cs probe) performed at $200 \mathrm{kV}$. The SEM samples were prepared by polishing the anodized $\mathrm{Al}$ foils and eroding them for $3 \mathrm{~min}$ in $\mathrm{KOH}$ solution. The TEM samples were thinned with a focused ion beam (FIB, versa 3D LoVac) to a thickness of about $100 \mathrm{~nm}$. The elemental distributions of the samples were examined by TEM coupled to energy-dispersive $\mathrm{X}$-ray spectroscopy (EDS). The cyclic voltammetry $\left(C_{\mathrm{y}} V\right)$ were conducted from -2 to $+2 \mathrm{~V}$ at sweep rate of $1 \mathrm{~V} / \mathrm{s}$ using a three-electrode system $(\mathrm{Ag} / \mathrm{AgCl}$ reference electrode, working electrode connected with samples, and Pt counter electrode) connected with a digital analyzer (VersaSTAT 3, Princeton Applied Research) and signals were monitored by a computer. The withstanding voltage and leakage current of the samples were measured using a source meter (2410, Keithley) and the capacitance were determined utilizing an impedance/ gain phase analyzer (4194A, Hewlett-Packard) in $\left(\mathrm{NH}_{4}\right)_{2} \mathrm{~B}_{10} \mathrm{O}_{16} \cdot 8 \mathrm{H}_{2} \mathrm{O}$ aqueous solution of $80 \mathrm{~g} / \mathrm{L}$ at $30{ }^{\circ} \mathrm{C}$.

\section{Results and discussion}

Figure 1(b) shows the conductivities of MPD-boric acid electrolytes at a series of temperatures. The conductivity of electrolyte rises with increasing the temperature. So, a higher ionic transport rate at higher temperature may be acquired, promoting the efficiency of anodization. Meanwhile, the ionic resistivities of the MPD-boric acid electrolytes correspondingly decrease as the temperature of electrolyte increase. The conductivity of the mixed electrolyte decreases as the ratio of MPD increase, because MPD exhibits high resistivity as shown in previous work [14]. The ionic migration are weakened and a relatively high voltage can be sustained as the conductivity of the solution decrease [16]. Therefore, it is expected that an electrolyte with a lower conductivity can facilitate anodization at a higher voltage but leads to a decrease in the anodization rate.

Figures 2(a)-(c) shows the SEM cross-sectional images of the dielectric oxides formed inside etch pits at different temperature. A compact combination between the coated $\mathrm{ZAO}$ layer (inner) and deposited $\mathrm{Al}_{2} \mathrm{O}_{3}$ layer (outer) is shown in each sample. The $\mathrm{Al}_{2} \mathrm{O}_{3}$ grows at both $\mathrm{Al} / \mathrm{ZrO}_{2}$ interface and $\mathrm{ZrO}_{2} /$ electrolyte interface by the transport of $\mathrm{Al}^{3+}$ coming from etched $\mathrm{Al}$ foils and $\mathrm{O}^{2-}$ coming from electrolyte under electric field. The outer $\mathrm{Al}_{2} \mathrm{O}_{3}$ layers demonstrates that the formation of $\mathrm{Al}_{2} \mathrm{O}_{3}$ is principally depending on the transport of $\mathrm{O}^{2-}$ ions under the driving force given by the electric field, further implying that the $\mathrm{O}^{2-}$ penetration in $\mathrm{ZrO}_{2}$-coated layer is much easier than $\mathrm{Al}^{3+}$. The total thicknesses of the dielectric oxides are approxi- (a)

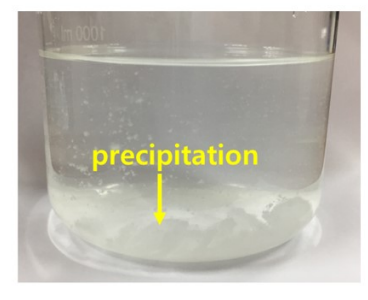

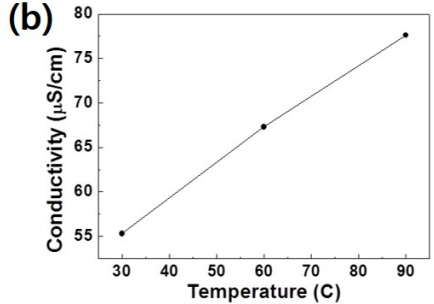

Figure 1. (Color online) (a) MPD-boric acid electrolyte at $25^{\circ} \mathrm{C}$. (b) Conductivity of the MPD-boric acid electrolyte at a series of temperatures.
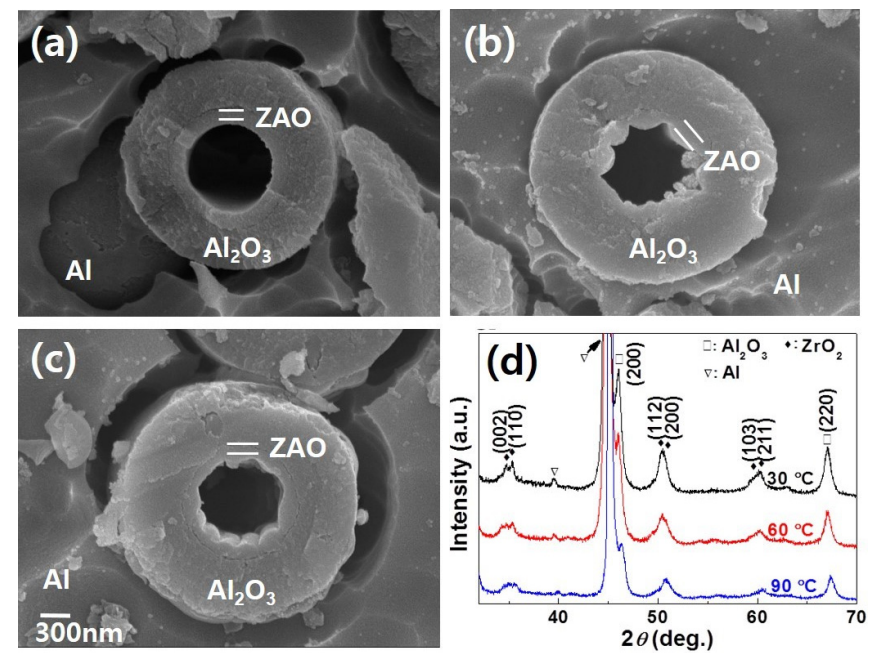

Figure 2. (Color online) SEM cross-sectional images of the oxide anodized at (a) 30 , (b) 60 , and (c) $90^{\circ} \mathrm{C}$. (d) XRD diffraction patterns of the samples anodized at different temperatures. 
mately 625, 680, and $750 \mathrm{~nm}$, increasing with enlargement of the conductivity at higher temperature. The electrolyte with a higher ionic resistivity of $1.8 \Omega / \mathrm{cm}$ at $30{ }^{\circ} \mathrm{C}$ can inhibit the ionic transport even more largely than the electrolyte with ionic resistivity of $1.2 \Omega / \mathrm{cm}$ at $90{ }^{\circ} \mathrm{C}$. After anodization at 30,60 , and $90{ }^{\circ} \mathrm{C}$, the thicknesses of the $\mathrm{Al}_{2} \mathrm{O}_{3}$ layer were approximately 440,590 , and $625 \mathrm{~nm}$, respectively. The ratio between the thickness of anodized $\mathrm{Al}_{2} \mathrm{O}_{3}$ layer and the anodizing voltage, $K$, has been reported to be approximately $1 \mathrm{~nm} / \mathrm{V}$ in pure $\mathrm{Al}$ [5]. In this work, these ratios were approximately $0.62,0.84$ and $0.89 \mathrm{~nm} / \mathrm{V}$ after anodizing at 30,60 , and $90{ }^{\circ} \mathrm{C}$, respectively. Lower $\mathrm{K}$ value in $\mathrm{ZrO}_{2}$-coated $\mathrm{Al}$ compared with $\mathrm{Al}$ specimens results from a hindrance in the movement of $\mathrm{Al}^{3+}$ and $\mathrm{O}^{2-}$ ions through $\mathrm{ZrO}_{2}$ layer.

Figure 2(d) shows the XRD diffraction patterns of the samples anodized at 30,60, and $90{ }^{\circ} \mathrm{C}$, respectively. The intensities of $\mathrm{Al}_{2} \mathrm{O}_{3}$ peaks are increased gradually, suggesting that the crystallization of $\mathrm{Al}_{2} \mathrm{O}_{3}$ is increased by making use of an electrolyte at lower temperature. This result may be explained that an electrolyte with a lower ionic conductivity require a higher applied potential on the $\mathrm{ZrO}_{2}-$ coated samples to reach at the constant current density of $0.1 \mathrm{~A} / \mathrm{cm}^{2}$ during anodization. That is, a higher electric field is needed on the $\mathrm{ZrO}_{2}$-coated $\mathrm{Al}$ foils, and the high electric field can effectively increase the nucleation rate, thereby promoting the crystallization of $\mathrm{Al}_{2} \mathrm{O}_{3}$. Also an increase in intensity of $\mathrm{ZrO}_{2}$ peaks after anodization suggests that coating layer is more crystallized during anodization. Since the same $\mathrm{ZrO}_{2}$ coating and annealing processes are applied, this phenomena proves that the anodization process can modify the crystallized $\mathrm{ZrO}_{2}$ by the way of re-crystallization. More detailed information about the re-crystallization of crystallize $\mathrm{ZrO}_{2}$ under the high electric field was presented in our previous work [17]. Herein, the difference of the crystallization of $\mathrm{Al}_{2} \mathrm{O}_{3}$ may also be due to the permeation of electrolyte species. Koyama et al. pointed out that the electrolyte component would intrude into the formed dielectrics and decrease with going deep into the dielectrics [18]. The transport rate of the electrolyte species increases at higher anodizing temperature. Therefore, high electrolyte temperature may enlarge the permeation rate of the electrolyte species thereby decreasing the crystallization.

Figures 3(a) and 3(b) show the TEM cross-sectional images and diffraction patterns of the $\mathrm{Al}_{2} \mathrm{O}_{3}$ formed in MPD-boric acid electrolyte at 30 and $90{ }^{\circ} \mathrm{C}$, respectively. The crystallinity of the $\mathrm{Al}_{2} \mathrm{O}_{3}$ anodized in the electrolyte of $30{ }^{\circ} \mathrm{C}$ is evidently higher than that formed in the electrolyte of $90{ }^{\circ} \mathrm{C}$ as corroborated by the diffraction patterns and visible $\mathrm{Al}_{2} \mathrm{O}_{3}$ grains in Fig. 3(a). This result also well agrees with the trend in the XRD diffraction patterns [Fig. 2(d)] that the anodization in the electrolyte of low temperature can effectively optimize the crystallization of $\mathrm{Al}_{2} \mathrm{O}_{3}$. A well crystallized samples could possibly raise the $\varepsilon_{\mathrm{r}}$ of the dielectrics. The micro-cracks marked with arrows in $\mathrm{Al}_{2} \mathrm{O}_{3}$ formed in the electrolyte of $30{ }^{\circ} \mathrm{C}$ [Fig. 3(a)] are not shown in sample anodized in the electrolyte of $90{ }^{\circ} \mathrm{C}$ [Fig. 3(b)], strongly proving that these micro-cracks are caused in the anodization process rather than in annealing process at $500{ }^{\circ} \mathrm{C}$ conducted after anodization. These micro-cracks may be associated with the tension generated by volume expansion in crystallization process. Indeed, the volume expansion accompanied by mechanical stresses is generated in anodization process [19]. Figure 3(c) shows the TEM-EDS depth profiles of the $\mathrm{O}, \mathrm{Al}$, and $\mathrm{Zr}$ species in the sample anodized in the MPD-boric acid electrolyte of $90{ }^{\circ} \mathrm{C}$. A profile of multi-layer structure from etch pit to $\mathrm{Al}$ substrate is viewed, which is $\mathrm{Al}_{2} \mathrm{O}_{3}$ layer of about $30 \mathrm{~nm}, \mathrm{ZAO}$ composite layer of about $100 \mathrm{~nm}, \mathrm{Al}_{2} \mathrm{O}_{3}$ layer of about

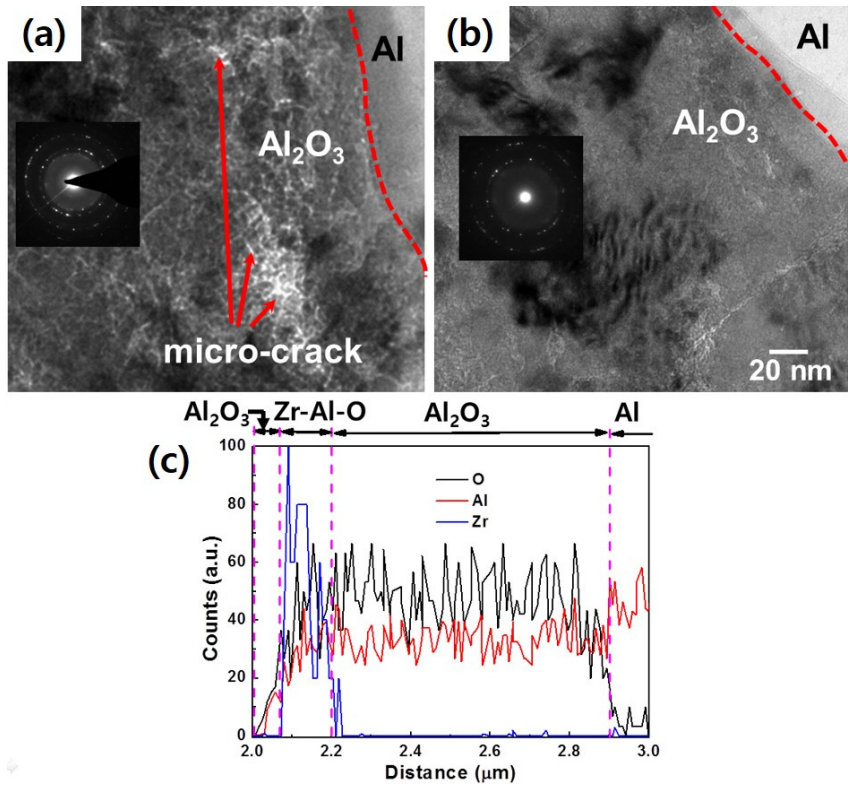

Figure 3. (Color online) TEM cross-sectional images and diffraction patterns of the $\mathrm{Al}_{2} \mathrm{O}_{3}$ anodized at (a) 30 and (b) $90{ }^{\circ} \mathrm{C}$. (c) EDS depth profiles of the sample formed at $90{ }^{\circ} \mathrm{C}$.
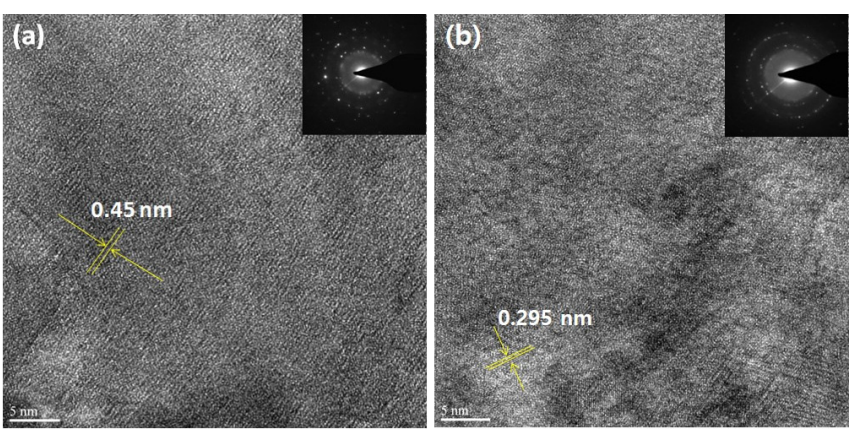

Figure 4. (Color online) HRTEM images and diffraction patterns of (a) $\mathrm{Al}_{2} \mathrm{O}_{3}$ and (b) $\mathrm{ZrO}_{2}$ in $\mathrm{ZAO}$ composite oxide layer formed at $30^{\circ} \mathrm{C}$.

$700 \mathrm{~nm}$, and $\mathrm{Al}$ substrate. The thickness of the dielectrics is slightly thicker than the thickness obtained from SEM images [Fig. 2] due to the corrosion in the $\mathrm{KOH}$ solution during the preparation process of the samples for SEM measurement. The EDS result further corroborates the anodization process mentioned above that $\mathrm{O}^{2-}$ ions ionized from the electrolyte transport through the $\mathrm{ZrO}_{2}$ coated layer to bond with $\mathrm{Al}^{3+}$ ions dissolved from the etched $\mathrm{Al}$ foils. Simultaneously, slight $\mathrm{Al}^{3+}$ ions dissolved from $\mathrm{Al}$ foils diffuse to the electrolyte through the $\mathrm{ZrO}_{2}$ coated layer to form $\mathrm{Al}_{2} \mathrm{O}_{3}$. The $\mathrm{Al}_{2} \mathrm{O}_{3}$ layer mostly is formed at the interface of $\mathrm{ZAO}$ composite layer/Al substrate, well agrees with the microstructure in the SEM images [Fig. 2].

Figure 4 shows the HRTEM images of (a) $\mathrm{Al}_{2} \mathrm{O}_{3}$ layer and (b) $\mathrm{ZrO}_{2}$ in $\mathrm{ZAO}$ composite layer anodized at $30^{\circ} \mathrm{C}$. The resolution of the HRTEM used in this study is $0.08 \mathrm{~nm}$. The measured interplanar spacing of the $\mathrm{Al}_{2} \mathrm{O}_{3}$ and separated crystalline $\mathrm{ZrO}_{2}$ is 0.45 and 0.295 $\mathrm{nm}$, respectively. These values are matched with the interplanar spacing of cubic $\mathrm{Al}_{2} \mathrm{O}_{3}$ (111) and tetragonal $\mathrm{ZrO}_{2}$ (101). $\mathrm{Al}_{2} \mathrm{O}_{3}$ layer is crystallized with clear lattice, but $\mathrm{ZAO}$ composite layer is composed of crystalline $\mathrm{ZrO}_{2}$ and amorphous $\mathrm{Al}_{2} \mathrm{O}_{3}$ as shown in our previous 


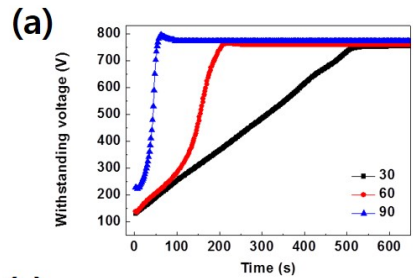

(c)
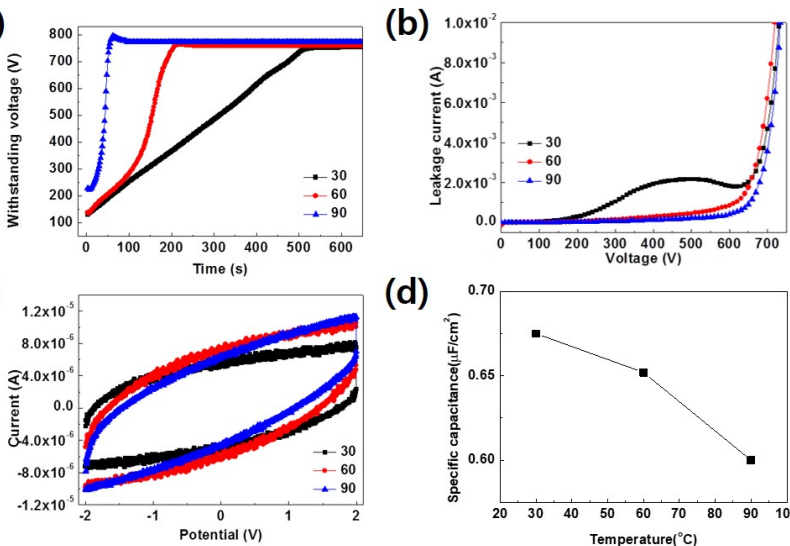

(d)

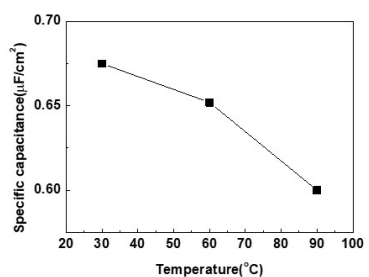

Figure 5. (Color online) (a) Withstanding voltage curves, (b) leakage current curves, (c) cyclic voltammetry curves of the samples anodized at variant temperatures. (d) Specific capacitances of the samples anodized at 30,60 , and $90{ }^{\circ} \mathrm{C}$.

report [20].

Figure 5(a) shows the withstanding voltage of the samples anodized in the electrolyte of 30,60 , and $90{ }^{\circ} \mathrm{C}$, respectively. The withstanding voltages are about $760 \mathrm{~V}$ and are almost regardless of the electrolyte temperature. Thus, the voltage sustain-abilities of the samples formed at 30,60 , and $90{ }^{\circ} \mathrm{C}$ are about $1.21,1.11$, and 1.01 $\mathrm{V} / \mathrm{nm}$, respectively. This demonstrates that the oxide with a higher crystallization has a greater voltage-sustainability than that with a lower crystallization. However, a longer time is needed in the potential evolution process for the samples anodized in the electrolyte of lower temperature. Moreover, correspondingly, the leakage currents in Fig. 5(b) also slightly increase in electrolyte of lower temperature. This appearance can be due to the consumption of stored charges, resulted from the micro-cracks generated in anodization process. However, the leakage currents of the samples are less than $0.01 \mathrm{~A}$ at applied voltage of $700 \mathrm{~V}$. Furthermore, in consideration of the self-repairing of the Al foil in charging process, over time, the leakage currents of the samples are supposed to diminish. Thus, the samples anodized at $30^{\circ} \mathrm{C}$ show better properties in terms of withstanding voltage and leakage current. To further evaluate the electrochemical properties of the samples, we carried out the cyclic voltammetry measurement [Fig. 5(c)]. A better capability is observed in the $\mathrm{ZrO}_{2}$-coated $\mathrm{Al}$ foils anodized in the electrolyte of lower temperature. Additionally, there are no evident redox peaks in the $C_{\mathrm{y}} V$ curves, suggesting that, independent of electrolyte temperature, a stable dielectric oxide layers is prepared after anodization in MPD-boric acid. Figure 5(d) shows the $C_{\mathrm{p}}$ of the samples anodized at 30,60 , and $90{ }^{\circ} \mathrm{C}$, respectively. The $C_{\mathrm{p}}$ of the samples decrease as the temperature of electrolytes become higher. A sensible enhancement in $C_{\mathrm{p}}$ is shown, which are the enlargements of $8.8 \%$ for anodization at $60{ }^{\circ} \mathrm{C}$ and $12.8 \%$ for anodization at $30{ }^{\circ} \mathrm{C}$ in comparison with the $C_{\mathrm{p}}$ values of the sample formed at $90{ }^{\circ} \mathrm{C}$. The increase in $C_{\mathrm{p}}$ of samples anodized at lower temperature may be owing to the decline in dielectric thickness, $d$ and the improvement in $\varepsilon_{\mathrm{r}}$ caused by the higher crystallinity of $\mathrm{Al}_{2} \mathrm{O}_{3}$ and $\mathrm{ZrO}_{2}$.

\section{Conclusions}

The effects of electrolyte temperature on the microstructure and electrical properties of the dielectrics on etched $\mathrm{Al}$ foils are explored.
The total thicknesses of the dielectric oxide layers increase with increasing the electrolyte temperatures. Additionally, the crystallizations of $\mathrm{ZrO}_{2}$ and $\mathrm{Al}_{2} \mathrm{O}_{3}$ were improved when samples were anodized at lower electrolyte temperature, meanwhile, more micro-cracks were observed in the $\mathrm{Al}_{2} \mathrm{O}_{3}$ layer formed at lower temperature. Moreover, the withstanding voltages are independent of the electrolyte temperature and leakage currents slightly enlarge with the decrease in electrolyte temperature. In comparison with the $C_{\mathrm{p}}$ value of the sample formed at $90{ }^{\circ} \mathrm{C}$, the $C_{\mathrm{p}}$ improvements of $8.8 \%$ at $60{ }^{\circ} \mathrm{C}$ and of $12.8 \%$ at $30{ }^{\circ} \mathrm{C}$ are achieved. The samples anodized at $30{ }^{\circ} \mathrm{C}$ in MPD: boric acid electrolyte with volume \% ratios of 3:10 show best properties.

\section{Acknowledgements}

This research was supported by Basic Science Research Program through the National Research Foundation of Korea (NRF) funded by the Ministry of Education (2017033541).

\section{References}

[1] J. K. Chang, C. M. Liao, C. H. Chen, and W. T. Tsai, J. Power Sources 138, 301 (2004).

[2] K. Watanabe, M. Sakairi, H. Takahashi, S. Hirai, and S. Yamaguchi, J. Electroanal. Chem. 473, 250 (1999).

[3] J. Ren and Y. Zuo, Appl. Surf. Sci. 261, 193 (2012).

[4] H. Habazaki, S. Koyama, Y. Aoki, N. Sakaguchi, and S. Nagata, ACS Appl. Mater. Interfaces 3, 2665 (2011).

[5] C. L. Ban, Y. D. He, and S. Xin, Trans. Nonferrous Met. Soc. China 21, 133 (2011).

[6] S. Ono, K. Kuramochi, and H. Asoh, Corros. Sci. 51, 1513 (2009).

[7] H. Takahashi, K. Fujimoto, and M. Nagayama, J. Electrochem. Soc. 135, 1349 (1988).

[8] C. Ban, Y. He, X. Shao, and Z. Wang, Corros. Sci. 78, 7 (2014).

[9] R. W. Santway and R. S. Alwitt, J. Electrochem. Soc. 117, 1282 (1970).

[10] M. Ue, H. Asahina, and S. Mori, J. Electrochem. Soc. 142, 2266 (1995).

[11] Y. Li, H. Shimada, M. Sakairi, K. Shigyo, H. Takahashi, and M. Seo, J. Electrochem. Soc. 144, 866 (1997).

[12] S. Stojadinovic, I. Belca, B. Kasalica, L. Zekovic, and M. Tadic, Electrochem. Commun. 8, 1621 (2006).

[13] J. T. Kinard, B. J. Melody, D. A. Wheeler, and P. M. Lessner, U.S. Patent 6,346,185 (2002).

[14] K. Zhang and S. S. Park, Surf. Coat. Technol. 310, 143 (2017).

[15] K. Watanabe, M. Sakairi, H. Takahashi, K. Takahiro, S. Nagata, and S. Hirai, J. Electrochem. Soc. 148, B473 (2001).

[16] X. L. Jin, X. Y. Wang, H. M. Zhang, Q. Xia, D. B. Wei, and J. J. Yue, Plasma Chem. Plasma Process. 30, 429 (2010).

[17] K. Zhang and S. S. Park, Thin Solid Films 636, 688 (2017).

[18] S. Koyama, Y. Aoki, S. Nagata, and H. Habazaki, J. Solid State Electrochem. 15, 2221 (2011).

[19] W. Lee and S. J. Park, Chem. Rev. 114, 7487 (2014).

[20] K. Zhang and S. S. Park, Appl. Surf. Sci. 477, 44 (2019). 